\title{
Insulin Tolerance Test Predicts the Effectiveness of Insulin Sensitizers in Japanese Type 2 Diabetic Patients
}

Junji Kozawa $\cdot$ Hiromi Iwahashi $\cdot$ Kohei Okita $\cdot$ Yukiyoshi Okauchi $\cdot$ Akihisa Imagawa $\cdot$ Iichiro Shimomura

Received: November 1, 2010 / Published online: January 19, 2011

(C) The Author(s) 2011. This article is published with open access at Springerlink.com

\section{ABSTRACT}

Introduction: The purpose of this study was to assess the efficacy of the insulin tolerance test (ITT) in predicting the effectiveness of insulin sensitizers in type 2 diabetic patients. Methods: We retrospectively reviewed 360 consecutive patients with type 2 diabetes admitted to Osaka University Hospital, Japan. In 163 of these hospitalized patients, insulin resistance was evaluated by the ITT after their blood glucose level was ameliorated. We then analyzed the association between their clinical characteristics and their glycemic control 6 months after discharge. Results: The rate constant for plasma glucose disappearance, $K_{\text {ITT }}$, was negatively correlated with body mass index (BMI), waist circumference (WC), and visceral fat area (VFA). The median value of $K_{\text {ITT }}$ was $1.56(\% / \mathrm{min})$. In the $K_{\text {ITT }}>1.56$ group $(n=81)$, hemoglobin $A_{1 \mathrm{c}}$

Junji Kozawa $(\bowtie) \cdot$ Hiromi Iwahashi · Kohei Okita •

Yukiyoshi Okauchi · Akihisa Imagawa · Iichiro

Shimomura

Department of Metabolic Medicine, Graduate School of Medicine, Osaka University, 2-2-B5 Yamadaoka, Suita

565-0871, Japan. Email: kjunji@endmet.med.osaka-u.ac.jp
$\left(\mathrm{HbA}_{1 \mathrm{c}}\right)$ significantly increased in both patients treated with insulin sensitizers $(n=10)$ and patients not treated with insulin sensitizers $(n=71)$. In the $K_{\text {ITT }} \leq 1.56$ group $(n=82), \mathrm{HbA}_{1 \mathrm{c}}$ significantly increased in patients not treated with insulin sensitizers ( $n=60)$; however, it was maintained well in the patients treated with insulin sensitizers $(n=22)$. When the patients were divided and analyzed according to the median values of BMI, WC, or VFA, the glycemic control change was not different between the two groups with insulin sensitizers for each parameter. Conclusion: Insulin sensitizers were effective in type 2 diabetic patients with high insulin resistance estimated by the ITT. The ITT could be useful to predict the effectiveness of insulin sensitizers.

Keywords: insulin resistance; insulin sensitizer; insulin tolerance test; type 2 diabetes

\section{INTRODUCTION}

Type 2 diabetes mellitus is characterized by decreased insulin secretion and insulin sensitivity in varying degrees. ${ }^{1-4}$ In Japanese diabetic patients, impaired insulin secretion is emphasized rather than insulin resistance, ${ }^{5}$ 
but insulin resistance also plays an important role in the deterioration of glucose tolerance. ${ }^{6,7}$ Recent studies have shown that the homeostasis model assessment of insulin resistance (HOMA-IR) in Japanese patients with type 2 diabetes was significantly higher than that for subjects with normal glucose tolerance. ${ }^{7,8}$ The prevalence of metabolic syndrome (MetS), which is characterized by insulin resistance ${ }^{9}$ defined by the criteria proposed by a Japanese study group, ${ }^{10}$ has reached as much as $45.9 \%$ in male and $28.0 \%$ in female Japanese type 2 diabetic patients. ${ }^{11}$ Therefore, it is important to consider insulin sensitizers in treating Japanese type 2 diabetics as well as insulin secretagogues. Insulin sensitizers, such as pioglitazone and metformin, are available, and are expected to improve glycemic control in patients with insulin resistance. However, it has not yet been fully clarified which characteristics in diabetic patients determine the efficiency of insulin sensitizers in each patient.

The euglycemic hyperinsulinemic clamp is regarded as the gold standard technique for measurement of in-vivo insulin action, ${ }^{12}$ but it requires sophisticated equipment, several hours of work, and considerable expense to use. By contrast, the insulin tolerance test (ITT) is simpler, easy to perform, and a more practical method than the clamp. The glucose disappearance rate calculated from the ITT $\left(K_{\text {ITT }}\right)$ has a close correlation with glucose clamp studies. ${ }^{13-15}$ We hypothesized that we could predict the effectiveness of insulin sensitizers in patients using the results of the ITT. In this study, we retrospectively reviewed consecutive subjects with type 2 diabetes mellitus admitted to Osaka University Hospital, Japan, whose insulin resistance had been evaluated by the ITT. We analyzed the association between the effectiveness of insulin sensitizers and $K_{\text {ITT }}$ in these patients.

\section{MATERIALS AND METHODS}

\section{Patients}

We retrospectively reviewed 360 consecutive subjects with type 2 diabetes mellitus admitted to Osaka University Hospital from 2001 to 2008. Following admission, all of the patients were treated by diet alone or diet plus insulin for at least 2 weeks, until fasting plasma glucose (FPG) was below $7.0 \mathrm{mmol} / \mathrm{L}$. After FPG reached the target level, insulin resistance was evaluated by the ITT, and 32 patients among them were treated with insulin sensitizers, according to the judgment of physicians. Then, we retrospectively analyzed the clinical characteristics and the glycemic control 6 months after discharge.

\section{Measurements}

The ITT was performed after an overnight fast, as previously described. ${ }^{13}$ Blood samples were collected every 3 minutes for 15 minutes after intravenous regular insulin injection $(0.1 \mathrm{U} / \mathrm{kg})$. The plasma glucose half-time $\left(t_{1 / 2}\right)$ was calculated from the slope of the least square analysis of the plasma glucose concentrations from 3 to 15 minutes after insulin injection. $K_{\text {ITT }}$ was calculated with the formula $0.693 / \mathrm{t}_{1 / 2}$.

A $75 \mathrm{~g}$ oral glucose tolerance test and a glucagon stimulation test were performed, as previously described. ${ }^{16}$ Plasma glucose concentrations were measured by the glucose oxidase method, and immunoreactive insulin and C-peptide levels were measured with enzyme immunoassay kits. For evaluation of glycemic control, the values of hemoglobin $\mathrm{A}_{1 \mathrm{c}}\left(\mathrm{HbA}_{1 \mathrm{c}}\right)$ at the time of discharge (or within 1 month after discharge) and 6 months after discharge and the increments of $\mathrm{HbA}_{1 \mathrm{c}}\left(\Delta \mathrm{HbA}_{1 \mathrm{c}}\right)$ between the two periods were used. The value for $\mathrm{HbA}_{1 \mathrm{c}}$ (\%) is estimated as a National Glycohemoglobin 
Standardization Program (NGSP) equivalent value (\%) calculated by the formula $\mathrm{HbA}_{1 \mathrm{c}}$ $(\%)=\mathrm{HbA}_{1 \mathrm{c}}$ (Japan Diabetes Society [JDS], \%)+ $0.4 \%$, considering the relational expression of $\mathrm{HbA}_{1 \mathrm{c}}$ (JDS, \%) measured by the previous Japanese standard substance and measurement methods and $\mathrm{HbA}_{1 \mathrm{c}}$ (NGSP). ${ }^{17}$ Plasma adiponectin levels were determined with an adiponectin enzymelinked immunosorbent assay (ELISA) kit (Otsuka Pharmaceutical Co. Ltd, Tokushima, Japan), as previously described. ${ }^{18}$ The visceral fat area (VFA) was estimated by computed tomography, or by abdominal bioelectrical impedance analysis, which was shown to correlate significantly with VFA determined by computed tomography. ${ }^{19}$

\section{Statistical Analyses}

Data are presented as the mean \pm standard deviation (SD). Comparison of variables between groups was done with the MannWhitney nonparametric test, or an unpaired Student's $t$ test. Pearson's correlation coefficient analysis was used to assess the cross-sectional relationships between $K_{\text {ITT }}$ and other variables. Comparison of $\mathrm{HbA}_{1 \mathrm{c}}$ at the time of discharge (or within 1 month after discharge) and 6 months after discharge in each group was done with a paired Student's $t$ test.

\section{RESULTS}

\section{Insulin Tolerance Test}

The ITT was performed in 163 out of 360 patients. The $K_{\text {ITT }}$ of these patients ranged from $0.39 \% /$ min to $8.9 \% / \mathrm{min}$, and the median value was $1.56 \% / \mathrm{min}$. The body mass index (BMI), waist circumference (WC), and VFA were negatively correlated with $K_{\text {ITT }}(r=-0.15, P=0.05 ; r=-0.25$, $P=0.003$; and $r=-0.23, P=0.02$, respectively) (Table 1).
Table 1. Correlation coefficients of relationships between $K_{\text {ITT }}$ and various parameters in type 2 diabetic patients.

\begin{tabular}{|c|c|c|}
\hline & $r$ & $P$ value \\
\hline Age, years & -0.06 & 0.43 \\
\hline Body mass index, $\mathrm{kg} / \mathrm{m}^{2}$ & -0.15 & 0.05 \\
\hline Waist circumference, $\mathrm{cm}$ & -0.25 & 0.003 \\
\hline Visceral fat area, $\mathrm{cm}^{2}$ & -0.23 & 0.02 \\
\hline $\mathrm{HbA}_{1 \mathrm{c}},(\%)^{*}$ & -0.05 & 0.53 \\
\hline Fasting plasma glucose, $\mathrm{mmol} / \mathrm{L} \dagger$ & -0.05 & 0.53 \\
\hline $\mathrm{HbA}_{1 \mathrm{c}}, \% \dagger$ & -0.04 & 0.62 \\
\hline Urine C-peptide, nmol/day & 0.09 & 0.26 \\
\hline Insulinogenic index, $\mathrm{pmol} / \mathrm{mmol}$ & 0.03 & 0.69 \\
\hline$\Delta \mathrm{C}$-peptide, $\mathrm{nmol} / \mathrm{L}$ & 0.09 & 0.31 \\
\hline Adiponectin, $\mu \mathrm{g} / \mathrm{mL}$ & 0.05 & 0.61 \\
\hline
\end{tabular}

*Value on admission.

†Value at the time of discharge or within 1 month after discharge.

$\mathrm{HbA}_{1 \mathrm{c}}=$ hemoglobin $\mathrm{A}_{1 \mathrm{c}} ; K_{\mathrm{ITT}}=$ rate constant for plasma glucose disappearance calculated from the insulin tolerance test; $r=$ Pearson's correlation coefficient.

\section{Patient Groups}

The patients were divided into two groups according to the median value of $K_{\mathrm{ITT}}: K_{\text {ITT }} \leq 1.56$ and $K_{\text {ITT }}>1.56$. Each of these two groups of patients were further divided into two subgroups according to treatment with or without insulin sensitizers at discharge. Insulin sensitizer treatment was with thiazolidinedione (pioglitazone) (TZD), biguanide (metformin or buformine) (BG), or both (TZD+BG). The $K_{\text {ITT }} \leq 1.56$ group $(n=82)$ included 22 patients treated with insulin sensitizers (TZD, $n=9 ; \mathrm{BG}, n=10 ; \mathrm{TZD}+\mathrm{BG}, n=3)$. The $K_{\text {ITT }}>1.56$ group ( $n=81$ ) included 10 patients treated with insulin sensitizers (TZD, $n=3 ; \mathrm{BG}, n=7$ ). Clinical data from these groups were investigated 6 months after discharge (Figure 1).

\section{Clinical Characteristics of the Patients}

The clinical characteristics of the patients of the $K_{\text {ITT }} \leq 1.56$ group and the $K_{\text {ITT }}>1.56$ group 
Figure 1. Management protocol for type 2 diabetic patients. After hospitalization, patients were treated until fasting plasma glucose (FPG) was below $7.00 \mathrm{mmol} / \mathrm{L}$. The insulin tolerance test (ITT) was performed in 163 of the patients to evaluate insulin resistance. According to the median value of the rate constant for plasma glucose disappearance calculated from the insulin tolerance test $\left(K_{\mathrm{ITT}} ; 1.56 \% / \mathrm{min}\right)$, the patients were divided into two groups: $K_{\mathrm{ITT}} \leq 1.56$ and $K_{\text {ITT }}>1.56$. These two groups were further divided into two subgroups: with or without insulin sensitizers at discharge. Insulin sensitizers were thiazolidinedione (pioglitazone) (TZD) and/or biguanide (metformin or buformine) (BG). Patient hemoglobin $A_{1 c}$ $\left(\mathrm{HbA}_{1 \mathrm{c}}\right)$ levels were evaluated at the time of discharge (or within 1 month after discharge) and 6 months later.

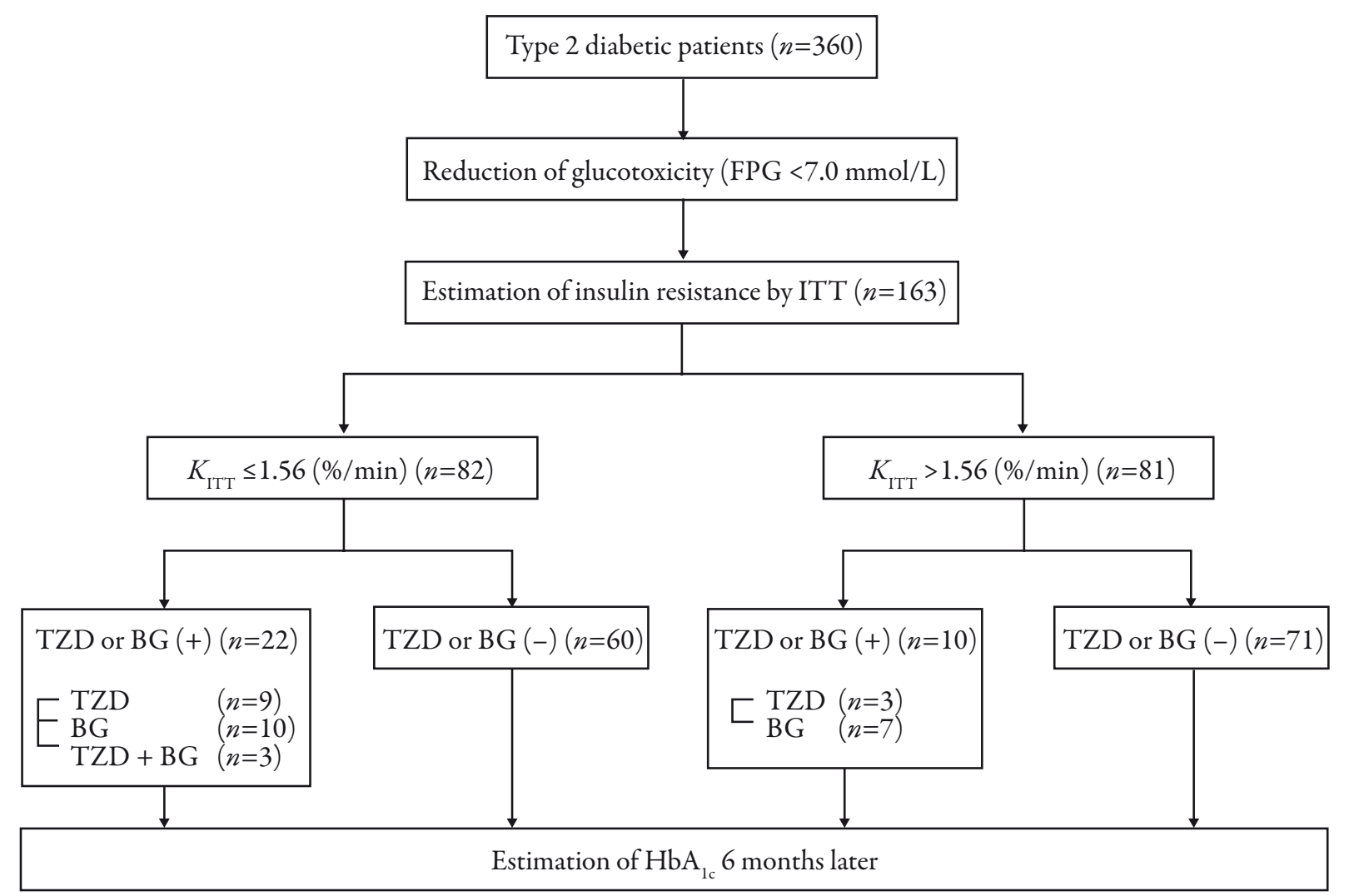

are shown in Table 2. VFA was significantly greater in the $K_{\text {ITT }} \leq 1.56$ group, compared with the $K_{\text {ITT }}>1.56$ group $(P<0.05)$. Other parameters were not significantly different between the two groups. The number of patients using insulin at discharge was 45 in the $K_{\text {ITT }} \leq 1.56$ group and 26 in the $K_{\text {IтT }}>1.56$ group, and patients with insulin secretagogues numbered 38 and 40, respectively. The clinical characteristics of the groups with and without insulin sensitizers in the $K_{\text {ITT }} \leq 1.56$ group and the $K_{\text {IтT }}>1.56$ group are shown in Table 3. There was no significant difference in the characteristics, including markers of insulin secretion and resistance, between the
$K_{\text {ITT }} \leq 1.56$ group with insulin sensitizers, and the $K_{\text {ITT }} \leq 1.56$ group without insulin sensitizers, as well as between the $K_{\text {ITT }}>1.56$ group with insulin sensitizers, and the $K_{\text {ITT }}>1.56$ group without insulin sensitizers. In the $K_{\text {ITT }} \leq 1.56$ group, the number of patients using insulin at discharge was three $(14 \%)$ in the group with insulin sensitizers, and 42 (70\%) in the group without insulin sensitizers. In the $K_{\text {ITT }}>1.56$ group, the number of patients using insulin at discharge was two (20\%) in the group with insulin sensitizers, and $24(34 \%)$ in the group without insulin sensitizers. In two groups with insulin sensitizers, the number of patients using treatment other 
Table 2. Clinical characteristics of the study subjects (total: $K_{\mathrm{ITT}} \leq 1.56$ and $K_{\mathrm{ITT}}>1.56$ ).

\begin{tabular}{|c|c|c|c|}
\hline & Total & $K_{\mathrm{ITT}} \leq 1.56$ & $K_{\mathrm{ITT}}>1.56$ \\
\hline$n$ (male/female) & $163(84 / 79)$ & $82(44 / 38)$ & $81(40 / 41)$ \\
\hline Age, years & $60.1 \pm 11.9$ & $60.1 \pm 11.5$ & $60.4 \pm 11.8$ \\
\hline Body mass index, $\mathrm{kg} / \mathrm{m}^{2}$ & $23.9 \pm 4.2$ & $24.5 \pm 4.7$ & $23.3 \pm 3.7$ \\
\hline Waist circumference, $\mathrm{cm}$ & $89.6 \pm 12.0(n=141)$ & $92.3 \pm 12.6^{*}(n=72)$ & $86.9 \pm 10.7(n=69)$ \\
\hline Visceral fat area, $\mathrm{cm}^{2}$ & $108.6 \pm 52.9(n=106)$ & $121.0 \pm 54.4^{*}(n=52)$ & $96.7 \pm 48.9(n=54)$ \\
\hline $\mathrm{HbA}_{\mathrm{lc}}, \% \dagger$ & $9.67 \pm 1.86$ & $9.82 \pm 1.66(n=81)$ & $9.63 \pm 1.77$ \\
\hline Fasting plasma glucose, $\mathrm{mmol} / \mathrm{L} \neq$ & $6.33 \pm 0.99$ & $6.44 \pm 0.90$ & $6.29 \pm 0.86$ \\
\hline $\mathrm{HbA}_{1 \mathrm{c}}, \% \neq$ & $7.13 \pm 0.90$ & $7.22 \pm 0.87$ & $7.04 \pm 0.92$ \\
\hline$K_{\mathrm{ITT}} \% / \mathrm{min}$ & $1.9 \pm 1.2$ & $1.1 \pm 0.3^{* *}$ & $2.7 \pm 1.3$ \\
\hline Urine C-peptide, nmol/day & $21.5 \pm 14.6(n=149)$ & $20.3 \pm 14.5(n=76)$ & $22.8 \pm 14.7(n=73)$ \\
\hline$\Delta \mathrm{C}$-peptide, $\mathrm{nmol} / \mathrm{L}$ & $0.72 \pm 0.41(n=130)$ & $0.68 \pm 0.42(n=65)$ & $0.75 \pm 0.39(n=65)$ \\
\hline Insulinogenic index, $\mathrm{pmol} / \mathrm{mmol}$ & $9.78 \pm 11.9(n=141)$ & $9.41 \pm 11.3(n=69)$ & $10.1 \pm 12.6(n=72)$ \\
\hline LDL-C, $\mathrm{mmol} / \mathrm{L}$ & $2.90 \pm 0.68(n=162)$ & $2.77 \pm 0.66^{*}$ & $3.04 \pm 0.68(n=80)$ \\
\hline $\mathrm{HDL}-\mathrm{C}, \mathrm{mmol} / \mathrm{L}$ & $1.26 \pm 0.36(n=162)$ & $1.22 \pm 0.34$ & $1.30 \pm 0.38(n=80)$ \\
\hline $\mathrm{TG}, \mathrm{mmol} / \mathrm{L}$ & $1.15 \pm 0.52(n=162)$ & $1.17 \pm 0.49$ & $1.14 \pm 0.55(n=80)$ \\
\hline $\mathrm{eGFR}, \mathrm{mL} / \mathrm{min} / 1.73 \mathrm{~m}^{2}$ & $87.7 \pm 25.7$ & $89.5 \pm 28.6$ & $85.8 \pm 22.3$ \\
\hline Adiponectin, $\mu \mathrm{g} / \mathrm{mL}$ & $5.4 \pm 3.3(n=121)$ & $4.9 \pm 2.5(n=57)$ & $5.8 \pm 3.8(n=64)$ \\
\hline
\end{tabular}

Data are mean $\pm S D$.

${ }^{*} P<0.05$.

${ }^{* *} P<0.0001 ; K_{\mathrm{ITT}} \leq 1.56$ versus $K_{\mathrm{ITT}}>1.56$.

†Value on admission.

‡Value at the time of discharge or within 1 month after discharge.

eGFR=estimated glomerular filtration rate; $\mathrm{HbA}_{1 \mathrm{c}}=$ hemoglobin $\mathrm{A}_{1 \mathrm{c}}$; $\mathrm{HDL}-\mathrm{C}=$ high-density lipoprotein cholesterol; $K_{\mathrm{ITT}}=$ rate constant for plasma glucose disappearance calculated from the insulin tolerance test; LDL-C=low-density lipoprotein cholesterol; TG=triglyceride.

than insulin sensitizers at discharge was 17 $(77.3 \%)$ for $K_{\text {ITT }} \leq 1.56$ and seven $(70 \%)$ for $K_{\text {ITT }}>1.56$. In the $K_{\text {ITT }} \leq 1.56$ group with insulin sensitizers, mean dosage of insulin sensitizers at the time of discharge was 23 (15-30) $\mathrm{mg} /$ day for pioglitazone, 750 (all 750) $\mathrm{mg} /$ day for metformin, and 112 (100-150) $\mathrm{mg} /$ day for buformine. In this group, mean dosage of insulin sensitizers 6 months after discharge was 25 (15-30) mg/ day for pioglitazone, 718 (500-750) $\mathrm{mg} /$ day for metformin, and 110 (100-150) mg/day for buformine. In the $K_{\text {ITT }}>1.56$ group with insulin sensitizers, mean dosage of insulin sensitizers at the time of discharge was $20(15-30) \mathrm{mg} /$ day for pioglitazone, 625 (500-750) mg/day for metformin, and 117 (100-150) $\mathrm{mg} /$ day for buformine. In this group, mean dosage of insulin sensitizers 6 months after discharge was 20 (15-30) $\mathrm{mg} /$ day for pioglitazone, 583 (500-750) $\mathrm{mg} /$ day for metformin, and 125 (100-150) mg/day for buformine.

\section{Glycemic Control After Discharge}

Glycemic control around the time of discharge and 6 months after discharge are shown in Table 4. The levels of $\mathrm{HbA}_{1 \mathrm{c}}$ significantly increased in the $K_{\text {ITT }} \leq 1.56$ group without insulin sensitizers $(7.3 \% \pm 0.9 \%$ to $8.0 \% \pm 1.7 \%, P=0.007)$, the $K_{\text {IтT }}>1.56$ group with insulin sensitizers 
Table 3. Clinical characteristics of the study subjects with and without insulin sensitizers ( $K_{\mathrm{ITT}} \leq 1.56$ and $\left.K_{\mathrm{ITT}}>1.56\right)$.

\begin{tabular}{|c|c|c|c|c|}
\hline & \multicolumn{2}{|c|}{$K_{\text {ITT }} \leq 1.56$} & \multicolumn{2}{|c|}{$K_{\text {ITT }}>1.56$} \\
\hline & TZD or BG $(+)$ & TZD or BG (-) & TZD or BG $(+)$ & TZD or BG (-) \\
\hline$n$ (male/female) & $22(12 / 10)$ & $60(32 / 28)$ & $10(8 / 2)$ & $71(32 / 39)$ \\
\hline Age, years & $59.9 \pm 11.9$ & $60.2 \pm 11.4$ & $62.7 \pm 14.3$ & $60.1 \pm 11.5$ \\
\hline Body mass index, $\mathrm{kg} / \mathrm{m}^{2}$ & $24.4 \pm 2.7$ & $24.5 \pm 5.2$ & $24.2 \pm 2.1$ & $23.2 \pm 5.8$ \\
\hline Waist circumference, $\mathrm{cm}$ & $91.7 \pm 9.3(n=19)$ & $92.5 \pm 13.7(n=53)$ & $91.5 \pm 7.8(n=9)$ & $86.2 \pm 11.0(n=60)$ \\
\hline Visceral fat area, $\mathrm{cm}^{2}$ & $118.7 \pm 43.5(n=16)$ & $122.1 \pm 59.2(n=36)$ & $115.2 \pm 52.1(n=6)$ & $94.4 \pm 48.6(n=48)$ \\
\hline $\mathrm{HbA}_{1 \mathrm{c}}, \% \dagger$ & $9.4 \pm 1.8(n=21)$ & $10.0 \pm 1.6$ & $9.5 \pm 2.2$ & $9.6 \pm 1.7$ \\
\hline Fasting plasma glucose, $\mathrm{mmol} / \mathrm{L} \neq$ & $6.43 \pm 0.91$ & $6.35 \pm 1.17$ & $6.26 \pm 0.82$ & $6.29 \pm 0.87$ \\
\hline $\mathrm{HbA}_{1 \mathrm{c}} \% \neq$ & $7.1 \pm 0.9$ & $7.3 \pm 0.9$ & $6.6 \pm 0.8$ & $7.1 \pm 0.9$ \\
\hline$K_{\mathrm{ITT}}, \% / \mathrm{min}$ & $1.2 \pm 0.3$ & $1.1 \pm 0.3$ & $2.2 \pm 0.8$ & $2.8 \pm 1.3$ \\
\hline Urine C-peptide, nmol/day & $20.2 \pm 14.8(n=19)$ & $20.3 \pm 14.6(n=57)$ & $24.9 \pm 12.8(n=8)$ & $22.6 \pm 15.0(n=65)$ \\
\hline$\Delta \mathrm{C}$-peptide, $\mathrm{nmol} / \mathrm{L}$ & $0.82 \pm 0.41(n=14)$ & $0.65 \pm 0.42(n=51)$ & $0.87 \pm 0.56(n=5)$ & $0.74 \pm 0.38(n=60)$ \\
\hline Insulinogenic index, $\mathrm{pmol} / \mathrm{mmol}$ & $11.0 \pm 11.8(n=19)$ & $8.8 \pm 11.1(n=50)$ & $12.4 \pm 8.2(n=8)$ & $9.9 \pm 13.1(n=64)$ \\
\hline LDL-C, $\mathrm{mmol} / \mathrm{L}$ & $2.89 \pm 0.76$ & $2.73 \pm 0.63$ & $2.91 \pm 0.44$ & $3.05 \pm 0.70(n=70)$ \\
\hline HDL-C, $\mathrm{mmol} / \mathrm{L}$ & $1.10 \pm 0.31^{*}$ & $1.26 \pm 0.34$ & $1.26 \pm 0.33$ & $1.31 \pm 0.39(n=70)$ \\
\hline $\mathrm{TG}, \mathrm{mmol} / \mathrm{L}$ & $1.21 \pm 0.41$ & $1.15 \pm 0.52$ & $1.26 \pm 0.45$ & $1.12 \pm 0.56(n=70)$ \\
\hline $\mathrm{eGFR}, \mathrm{ml} / \mathrm{min} / 1.73 \mathrm{~m}^{2}$ & $85.1 \pm 22.9$ & $91.1 \pm 30.4$ & $84.2 \pm 21.7$ & $86.0 \pm 22.5$ \\
\hline Adiponectin, $\mu \mathrm{g} / \mathrm{mL}$ & $4.8 \pm 2.2(n=11)$ & $4.9 \pm 2.6(n=46)$ & $5.6 \pm 2.1(n=6)$ & $5.8 \pm 4.0(n=58)$ \\
\hline
\end{tabular}

Data are mean \pm SD.

${ }^{*} P<0.05, K_{\mathrm{ITT}} \leq 1.56$, TZD or BG $(+)$ versus $K_{\mathrm{ITT}} \leq 1.56$, TZD or BG $(-)$.

†Value on admission.

$\neq$ Value at the time of discharge or within 1 month after discharge.

$\mathrm{BG}=$ biguanide (metformin or buformine); $\mathrm{eGFR}=$ estimated glomerular filtration rate; $\mathrm{HbA}_{\mathrm{lc}}=$ hemoglobin $\mathrm{A}_{\mathrm{lc}}$;

HDL-C $=$ high-density lipoprotein cholesterol; $K_{\text {ITT }}=$ rate constant for plasma glucose disappearance calculated from the insulin tolerance test; LDL-C=low-density lipoprotein cholesterol; TG=triglyceride; TZD=thiazolidinedione (pioglitazone).

$(6.6 \% \pm 0.8 \%$ to $7.3 \% \pm 1.1 \%, P=0.025)$, and the $K_{\text {ITT }}>1.56$ group without insulin sensitizers (7.1\% $\pm 0.9 \%$ to $7.4 \% \pm 1.5 \%, P=0.022)$. However, $\mathrm{HbA}_{1 \mathrm{c}}$ did not increase in the $K_{\text {ITT }} \leq 1.56$ group with insulin sensitizers $(7.1 \% \pm 0.9 \%$ to $7.0 \% \pm 0.9 \%, P=$ not significant [NS]) (Table 4). In the $K_{\text {ITT }} \leq 1.56$ group without insulin sensitizers, the $\Delta \mathrm{HbA}_{1 \mathrm{c}}(0.7 \% \pm 1.6 \%)$ was higher than that in the $K_{\text {ITT }} \leq 1.56$ group with insulin sensitizers $(-0.1 \% \pm 1.3 \%)$, but the difference was NS $(P=0.087)$. Respective $\mathrm{HbA}_{1 \mathrm{c}}$ changes in these subgroups are shown in Figure 2.

When all of the patients were divided into two groups according to the median value of BMI (BMI $\geq 23.2$, BMI <23.2), WC (WC $\geq 90.5$,
WC <90.5), or VFA (VFA $\geq 104.9$, VFA < 104.9), the levels of $\mathrm{HbA}_{1 \mathrm{c}}$ did not change in both groups with insulin sensitizers (Table 4). When they were divided into two groups according to the values based on the obesity or abdominal obesity criteria of BMI (BMI $\geq 25, \mathrm{BMI}<25$ ), WC (WC $\geq 85$ in men and WC $\geq 90$ in women, $\mathrm{WC}<85$ in men and $\mathrm{WC}<90$ in women), or VFA (VFA $\geq 100$, VFA $<100$ ) in Japan, the results were the same as above (data not shown).

\section{DISCUSSION}

In this study, we have shown the possible usefulness of ITT for selecting patients for 
Table 4. Glycemic control after discharge in all of the patients.

\begin{tabular}{|c|c|c|c|c|c|}
\hline & & At discharge* & After discharget (\%) & $\Delta \mathrm{HbA}_{1 \mathrm{c}}(\%)$ & $P$ value (\%) \\
\hline \multirow{2}{*}{$K_{\mathrm{ITT}} \leq 1.56, \% / \mathrm{min}$} & TZD or BG $(+)(n=22)$ & $7.1 \pm 0.9$ & $7.0 \pm 0.9$ & $-0.1 \pm 1.3$ & NS \\
\hline & TZD or BG $(-)(n=60)$ & $7.3 \pm 0.9$ & $8.0 \pm 1.7$ & $0.7 \pm 1.6$ & 0.0007 \\
\hline \multirow{2}{*}{$K_{\mathrm{ITT}}>1.56, \% / \mathrm{min}$} & TZD or BG $(+)(n=10)$ & $6.6 \pm 0.8$ & $7.3 \pm 1.1$ & $0.7 \pm 0.9$ & 0.025 \\
\hline & TZD or BG $(-)(n=71)$ & $7.1 \pm 0.9$ & $7.4 \pm 1.5$ & $0.3 \pm 1.2$ & 0.022 \\
\hline \multirow[t]{2}{*}{$\mathrm{BMI} \geq 23.2, \mathrm{~kg} / \mathrm{m}^{2}$} & TZD or BG $(+)(n=18)$ & $6.9 \pm 1.0$ & $7.0 \pm 1.1$ & $0.1 \pm 1.5$ & NS \\
\hline & TZD or BG $(-)(n=64)$ & $7.3 \pm 0.9$ & $7.9 \pm 1.9$ & $0.6 \pm 1.8$ & 0.014 \\
\hline \multirow[t]{2}{*}{$\mathrm{BMI}<23.2, \mathrm{~kg} / \mathrm{m}^{2}$} & TZD or BG $(+)(n=14)$ & $7.0 \pm 0.8$ & $7.3 \pm 0.8$ & $0.3 \pm 0.9$ & NS \\
\hline & TZD or BG $(-)(n=67)$ & $7.1 \pm 0.8$ & $7.5 \pm 1.4$ & $0.5 \pm 1.0$ & 0.0001 \\
\hline \multirow[t]{2}{*}{$\mathrm{WC} \geq 90.5, \mathrm{~cm}$} & TZD or BG $(+)(n=16)$ & $6.8 \pm 1.0$ & $6.9 \pm 1.1$ & $0.1 \pm 1.5$ & NS \\
\hline & TZD or BG $(-)(n=55)$ & $7.3 \pm 1.0$ & $8.0 \pm 2.0$ & $0.6 \pm 1.8$ & 0.013 \\
\hline \multirow[t]{2}{*}{$\mathrm{WC}<90.5, \mathrm{~cm}$} & TZD or BG $(+)(n=12)$ & $7.0 \pm 0.8$ & $7.4 \pm 0.7$ & $0.3 \pm 0.9$ & NS \\
\hline & TZD or BG $(-)(n=58)$ & $7.0 \pm 0.9$ & $7.4 \pm 1.2$ & $0.4 \pm 0.9$ & 0.001 \\
\hline \multirow[t]{2}{*}{$\mathrm{VFA} \geq 104.9, \mathrm{~cm}^{2}$} & TZD or BG $(+)(n=13)$ & $7.1 \pm 1.0$ & $7.2 \pm 1.0$ & $0.1 \pm 1.7$ & NS \\
\hline & TZD or BG $(-)(n=40)$ & $7.4 \pm 0.9$ & $8.1 \pm 2.0$ & $0.6 \pm 1.8$ & 0.032 \\
\hline \multirow[t]{2}{*}{$\mathrm{VFA}<104.9, \mathrm{~cm}^{2}$} & TZD or BG $(+)(n=9)$ & $6.9 \pm 1.0$ & $7.0 \pm 0.9$ & $0.1 \pm 1.1$ & NS \\
\hline & TZD or BG $(-)(n=44)$ & $7.0 \pm 0.9$ & $7.4 \pm 1.3$ & $0.4 \pm 1.0$ & 0.027 \\
\hline
\end{tabular}

Data are mean \pm SD.

*At the time of discharge or within 1 month after discharge.

tAt 6 months after discharge; $\Delta \mathrm{HbA}_{\mathrm{lc}}$ was calculated from $\mathrm{HbA}_{\mathrm{lc}} 6$ months after discharge minus that at the time of discharge or within 1 month after discharge.

$\mathrm{BG}=$ biguanide (metformin or buformine); $\mathrm{BMI}=$ body mass index; $\mathrm{HbA}_{\mathrm{lc}}=$ hemoglobin $\mathrm{A}_{1 \mathrm{c}} ; K_{\mathrm{ITT}}=$ rate constant for plasma glucose disappearance calculated from the insulin tolerance test; $\mathrm{NS}=$ not significant; $\mathrm{TZD}=$ thiazolidinedione (pioglitazone); $\mathrm{VFA}=$ visceral fat area; $\mathrm{WC}=$ waist circumference.

whom insulin sensitizers are effective for glycemic control. With insulin sensitizers, the glycemic control worsened in the group with a higher value of $K_{\text {ITT}}$, but was maintained well in the group with a lower value of $K_{\text {ITT }}$. There was also a tendency to keep good glycemic control after discharge with insulin sensitizers in the latter group, compared with in the former group. By contrast, the other parameters studied (BMI, WC, and VFA) were not useful for determining the effectiveness of insulin sensitizers. In previous reports, rosiglitazone, which is one of the TZDs, and metformin were effective for glycemic control of type 2 diabetic patients with and without obesity, defined by BMI. ${ }^{20,21}$ These results, in addition to ours, suggest that parameters other than $K_{\text {ITT }}$ could not clearly discriminate the patients regarding the effectiveness of insulin sensitizers. It is speculated that $K_{\text {ITT }}$ represents in-vivo insulin action in the whole body directly, ${ }^{13}$ while other parameters do not, though these parameters are regarded as the factors associated with insulin resistance. In our study, BMI, WC, and VFA had low correlation coefficients with $K_{\text {ITT }}$. In other previous reports, BMI and waist-to-hip ratio were not related to insulin resistance estimated by $K_{\mathrm{ITT}}{ }^{22}$ These results suggest that BMI, WC, and VFA may cause or reflect some partial aspects of insulin resistance. 
Figure 2. Glycemic control after discharge. Glycemic control around the time of discharge and 6 months after discharge are shown. The levels of hemoglobin $\mathrm{A}_{1 \mathrm{c}}\left(\mathrm{HbA}_{\mathrm{lc}}\right)$ significantly increased in the rate constant for plasma glucose disappearance calculated from the insulin tolerance test $\left(K_{\mathrm{ITT}}\right) \leq 1.56$ without insulin sensitizers group, the $K_{\mathrm{ITT}}>1.56$ with insulin sensitizers group and the $K_{\text {ITT }}>1.56$ without insulin sensitizers group. However, $\mathrm{HbA}_{\mathrm{lc}}$ did not increase in the $K_{\mathrm{ITT}} \leq 1.56$ with insulin sensitizers group. $\mathrm{BG}=$ biguanide (metformin or buformine); $\mathrm{NS}=$ not significant; $\mathrm{TZD}=$ thiazolidinediones (pioglitazone).

$$
\begin{gathered}
K_{\text {ITT }} \leq 1.56 \\
\text { TZD or BG }(+)
\end{gathered}
$$

(\%)

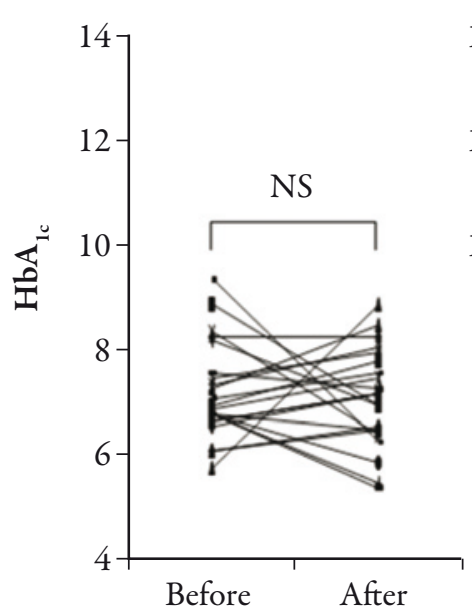

$$
K_{\text {ITT }} \leq 1.56
$$$$
\text { TZD or BG (-) }
$$

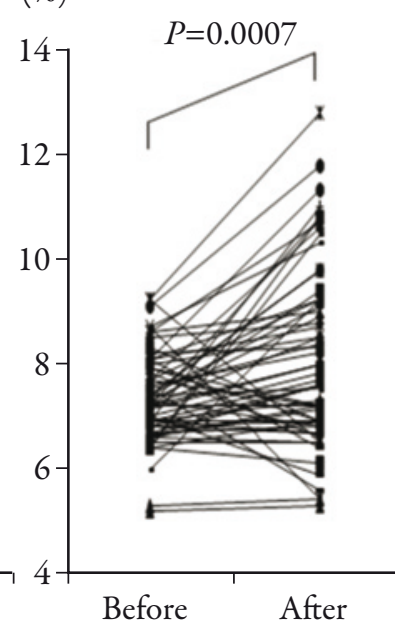

(\%)

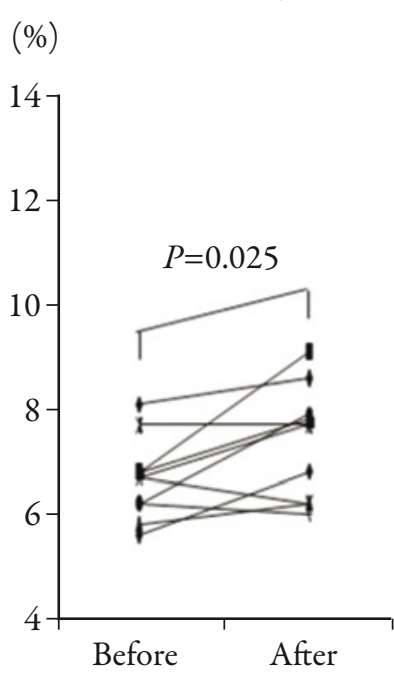

$K_{\mathrm{ITT}}>1.56$

TZD or BG (+)

$$
\begin{gathered}
K_{\text {ITT }}>1.56 \\
\text { TZD or BG }(-)
\end{gathered}
$$

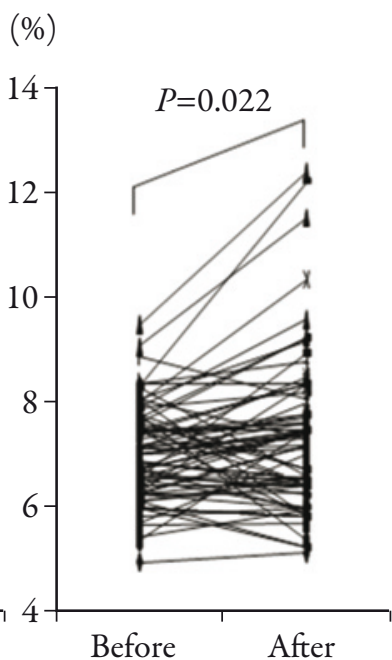

In this study, we evaluated patients' insulin resistance after hyperglycemia was ameliorated. Defects in insulin action were induced only after 24 hours of hyperglycemia in patients with type 1 diabetes. ${ }^{23}$ Insulin treatment for 4 weeks and good glycemic control improved insulin resistance in patients with uncontrolled type 2 diabetes. ${ }^{24}$ Those studies indicated that hyperglycemia worsens insulin resistance, and that this augmented resistance could be recovered after glycemic control was improved. Therefore, we propose that the evaluation of insulin resistance should be performed after the amelioration of glycemic control.

In this study, we also analyzed the association between the effectiveness of insulin sensitizers and HOMA-IR, which was regarded as the reference parameter in cases with insulin therapy. When all of the patients were divided into two groups according to the median value of HOMA-IR (HOMA-IR $\geq 1.75$, HOMA-IR $<1.75$ ), the levels of $\mathrm{HbA}_{1 \mathrm{c}}$ did not change in both

groups with insulin sensitizers, indicating that HOMA-IR was not also useful for determining the effectiveness of insulin sensitizers. HOMA-IR represents an index of the hepatic insulin sensitivity in the basal state, ${ }^{25}$ which does not necessarily parallel peripheral insulin sensitivity, ${ }^{26}$ while $K_{\text {IтT }}$ represents in-vivo insulin action in the whole body directly. ${ }^{13}$ Indeed, the association between insulin resistance obtained from the homeostasis model assessment and the ITT was significant but quite low, ${ }^{27}$ suggesting that these two parameters represent different aspects of the insulin resistance.

There are some study limitations to consider. First, this is a retrospective study, and we could not discriminate the effect of any medication other than insulin sensitizers, especially insulin, on glycemic control after discharge. However, the ratio of patients using insulin in the $K_{\text {ITT }} \leq 1.56$ group with insulin sensitizers was not higher than those of other groups. Similarly, the ratio of patients using treatment other than insulin 
sensitizers was the same as that in the $K_{\text {ITT }}>1.56$ group with insulin sensitizers. Therefore, the good glycemic control obtained in the $K_{\text {ITT }} \leq 1.56$ group with insulin sensitizers might be derived from the higher insulin resistance estimated by ITT, and the efficacy of insulin sensitizers. Also, patients with insulin sensitizers were not selected at random. The numbers of patients with insulin sensitizers in the $K_{\text {ITT }} \leq 1.56$ and the $K_{\text {ITT }}>1.56$ groups are different and small. However, our data showed the significant difference of the effectiveness of insulin sensitizers among these subgroups.

\section{CONCLUSION}

In summary, insulin sensitizers were more effective for glycemic control in type 2 diabetic patients with higher insulin resistance estimated by the ITT. The ITT could be useful for predicting the effectiveness of insulin sensitizers. Further prospective studies are needed to confirm the usefulness of the ITT.

\section{ACKNOWLEDGMENTS}

The authors declare no financial support or relationship that may pose a conflict of interest. We thank T. Funahashi, M. Moriwaki, T. Nammo, K. Kishida, H. Nishizawa, M. Kumada, S. Uno, K. Fukui, A. Hiuge, Y. Imamura, A. Katada, N. Komura, K. Sayama, Y. Tokui, I. Hayashi, K. Fujita, S. Kashine, Y. Kuroda, H. Shoda, S. Umemura, Y. Okamoto, S. Tamba, A. Tokunaga, S. Nakata, A. Hirata, E. Fukuda-Akita, K. Saisho, Y. Inomata-Kurashiki, H. Nakatsuji, T. Natsukawa, A. Yoshikawa, T. Kajimoto and T. Kimura for their valuable help with this study.

Open Access. This article is distributed under the terms of the Creative Commons Attribution Noncommercial License which permits any noncommercial use, distribution, and reproduction in any medium, provided the original author(s) and source are credited.

\section{REFERENCES}

1. Cavaghan MK, Ehrmann DA, Polonsky KS. Interaction between insulin resistance and insulin secretion in the development of glucose intolerance. J Clin Invest. 2000;106:329-333.

2. Fujimoto WY. The importance of insulin resistance in the pathogenesis of type 2 diabetes mellitus. Am J Med. 2000;108(suppl. 6A):9S-14S.

3. Abdul-Ghani MA, Tripathy D, DeFronzo RA. Contributions of beta-cell dysfunction and insulin resistance to the pathogenesis of impaired glucose tolerance and impaired fasting glucose. Diabetes Care. 2006;29:1130-1139.

4. Fukushima M, Usami M, Ikeda M, et al. Insulin secretion and insulin sensitivity at different stages of glucose tolerance: a cross-sectional study of Japanese type 2 diabetes. Metabolism. 2004;53:831835.

5. Suzuki H, Fukushima M, Usami M, et al. Factors responsible for development from normal glucose tolerance to isolated post challenge hyperglycemia. Diabetes Care. 2003;26:1211-1215.

6. Mitsui R, Fukushima M, Nishi $\mathrm{Y}$, et al. Factors responsible for deteriorating glucose in newly diagnosed type 2 diabetes in Japanese men. Metabolism. 2006;55:53-58.

7. Kanauchi M, Nakajima M, Saito Y, Kanauchi K. Pancreatic beta-cell function and insulin sensitivity in Japanese subjects with impaired glucose tolerance and newly diagnosed type 2 diabetes mellitus. Metabolism. 2003;52:476-481.

8. Matsuhisa M, Yamasaki Y, Emoto M, et al. A novel index of insulin resistance determined from the homeostasis model assessment index and adiponectin levels in Japanese subjects. Diabetes Res Clin Pract. 2007;77:151-154.

9. Funahashi T, Matsuzawa Y. Metabolic syndrome: clinical concept and molecular basis. Ann Med. 2007;39:482-494.

10. Study group for definition of metabolic syndrome, definition and diagnostic criteria of metabolic syndrome. J Jpn Soc Intern Med. 2005;94:188-203. 
11. Shimajiri Y, Tsunoda K, Furuta M, et al. Prevalence of metabolic syndrome in Japanese type 2 diabetic patients and its significance for chronic vascular complications. Diabetes Res Clin Pract. 2008;79:310-317.

12. Donner CC, Fraze E, Chen YD, Reaven GM. Quantitation of insulin-stimulated glucose disposal in patients with non-insulin-dependent diabetes mellitus. Diabetes. 1985;34:831-835.

13. Bonora E, Moghetti P, Zancanaro C, et al. Estimates of in vivo insulin action in man: comparison of insulin tolerance tests with euglycemic and hyperglycemic glucose clamp studies. J Clin Endocrinol Metab. 1989;68:374-378.

14. Akinmokun A, Selby PL, Ramaiya K, Alberti KG. The short insulin tolerance test for determination of insulin sensitivity: a comparison with the euglycaemic clamp. Diabet Med. 1992;9:432-437.

15. Gelding SV, Robinson S, Lowe S, Niththyananthan $\mathrm{R}$, Johnston DG. Validation of the low dose short insulin tolerance test for evaluation of insulin sensitivity. Clin Endocrinol (Oxf). 1994;40:611615.

16. Fukuda-Akita E, Okita K, Okauchi Y, et al. Impaired early insulin secretion in Japanese type 2 diabetes with metabolic syndrome. Diabetes Res Clin Pract. 2008;79:482-489.

17. The Committee of Japan Diabetes Society on the diagnostic criteria of diabetes mellitus. Report of the Committee on the classification and diagnostic criteria of diabetes mellitus. J Jpn Diabetes Soc. 2010;53:450-467.

18. Arita Y, Kihara S, Ouchi N, et al. Paradoxical decrease of an adipose-specific protein, adiponectin, in obesity. Biochem Biophys Res Commun. 1999;257:79-83.

19. Ryo M, Maeda K, Onda T, et al. A new simple method for the measurement of visceral fat accumulation by bioelectrical impedance. Diabetes Care. 2005;28:451-453.

20. Jones TA, Sautter M, Van Gaal LF, Jones NP. Addition of rosiglitazone to metformin is most effective in obese, insulin-resistant patients with type 2 diabetes. Diabetes Obes Metab. 2003;5:163170.

21. DeFronzo RA, Barzilai N, Simonson DC. Mechanism of metformin action in obese and lean noninsulindependent diabetic subjects. J Clin Endocrinol Metab. 1991;73:1294-1301.

22. Gautier JF, Mourier A, de Kerviler E, et al. Evaluation of abdominal fat distribution in noninsulindependent diabetes mellitus: relationship to insulin resistance. J Clin Endocrinol Metab. 1998;83:13061311.

23. Vuorinen-Markkola H, Koivisto VA, Yki-Jarvinen H. Mechanisms of hyperglycemia-induced insulin resistance in whole body and skeletal muscle of type 1 diabetic patients. Diabetes. 1992;41:571580.

24. Pouwels MJ, Span PN, Tack CJ, et al. Muscle uridine diphosphate-hexosamines do not decrease despite correction of hyperglycemia-induced insulin resistance in type 2 diabetes. J Clin Endocrinol Metab. 2002;87:5179-5184.

25. Wallace TM, Matthews DR. The assessment of insulin resistance in man. Diabet Med. 2002;19:527-534.

26. Matsuda M, DeFronzo RA. Insulin sensitivity indices obtained from oral glucose tolerance testing. Comparison with the euglycaemic insulin clamp. Diabetes Care. 1999;22:1462-1470.

27. Inchiostro S. Measurement of insulin sensitivity in type 2 diabetes mellitus: comparison between KITT and HOMA- $\%$ S indices and evaluation of their relationship with the components of the insulin resistance syndrome. Diabet Med. 2005;22:39-44. 